\title{
CME Endocrinology (108461): self-assessment questionnaire
}

\author{
Edited by John Newell-Price and Tahseen A Chowdhury
}

SAQs and answers are ONLINE for RCP fellows and collegiate members

SAQs and answers are ONLINE for RCP fellows and collegiate members

\section{Format}

Candidates are asked to choose the best answer from the five possible answers. This best of five format is used in many medical examinations, however the questions are not intended to be representative of those used in the MRCP(UK) Part 1 or Part 2 Written Examinations.

\section{The answering process}

1 Go to www.rcplondon.ac.uk/SAQ

2 Log on using your usual RCP username and password

3 Select the relevant CME question paper

4 Answer all 10 questions by selecting the best answer from the options provided

5 Once you have answered all the questions, click on Submit

\section{Registering your external CPD credits}

Carrying out this activity allows you to claim two external CPD credits. These will be automatically transferred to your CPD diary, where you can review the activity and claim your points.

1 A 32-year-old woman was admitted to hospital because of dizziness and weakness following 36 hours of vomiting and diarrhoea, which was ongoing. She had taken levothyroxine treatment for hypothyroidism for the last 5 years.

On examination, she was thin, with decreased skin turgor. Her pulse was $125 \mathrm{bpm}$ and blood pressure was $92 / 58 \mathrm{mmHg}$. There was diffuse abdominal tenderness but no guarding or focal signs. Bowel sounds were active. Serum sodium was $121 \mathrm{mmol} / \mathrm{L}$, potassium $3.6 \mathrm{mmol} / \mathrm{L}$, urea $7.9 \mathrm{mmol} / \mathrm{L}$, creatinine $147 \mu \mathrm{mol} / \mathrm{L}$ and glucose $3.2 \mathrm{mmol} / \mathrm{L}$.

The optimal next step in her management is:

(a) administer intravenous 5\% dextrose and intramuscular cyclizine

(b) administer intravenous $0.9 \%$ saline and intramuscular hydrocortisone

(c) administer intravenous $0.9 \%$ saline and oral loperamide

(d) order a plasma adrenocorticotropic hormone, serum cortisol and thyroid-stimulating hormone measurement

(e) perform a short synacthen test.
2 An 18-year-old man with longstanding primary adrenal failure mentioned that he had suffered from three episodes of adrenal crisis in the last 4 months. He had started university and joined the athletics club and was in training for a half-marathon, having previously only run shorter distances. In between the episodes of adrenal crisis he felt well. He took hydrocortisone $20 \mathrm{mg}$ daily in split doses and fludrocortisone $100 \mu \mathrm{g}$ daily. He denied ever missing doses.

He had a fitness watch and reported that his resting pulse rate used to be $56 \mathrm{bpm}$ but since he had started training it had gradually increased to $72 \mathrm{bpm}$. Blood pressure was $102 / 62 \mathrm{mmHg}$. Serum sodium was $133 \mathrm{mmol} / \mathrm{L}$, potassium $5.0 \mathrm{mmol} / \mathrm{L}$, urea $4.9 \mathrm{mmol} / \mathrm{L}$, creatinine $107 \mu \mathrm{mol} / \mathrm{L}$ and thyroid-stimulating hormone $1.49 \mathrm{mU} / \mathrm{L}$.

He is best advised to:

(a) make no change in his present medication doses

(b) increase his daily fludrocortisone dose to $200 \mu \mathrm{g}$

(c) increase his daily hydrocortisone dose to $30 \mathrm{mg}$

(d) take an extra $5 \mathrm{mg}$ of hydrocortisone before exercise

(e) use an isotonic sports drink following exercise.

3 A 76-year-old man was admitted with pyrexia, constipation and lower abdominal pain. He had tenderness and guarding in the left iliac fossa, with no bowel sounds. Following a contrast computerised tomography scan, an acute diverticular abscess of the sigmoid colon was diagnosed. He was kept nil by mouth, with a nasogastric tube and appropriate antibiotic treatment was started. He had a history of polymyalgia rheumatica treated with steadily reducing doses of oral prednisolone for the last 3 years. He had been on his current dose of $6 \mathrm{mg}$ daily for the last 4 months.

How should his steroid therapy be managed?

(a) Administer double his usual oral prednisolone dose.

(b) Administer his usual oral prednisolone dose.

(c) Administer intravenous hydrocortisone $100 \mathrm{mg}$ stat.

(d) Prednisolone should be discontinued for 48 hours while he has sepsis.

(e) Steroids are a risk factor for perforation and should be stopped.

4 A 52-year-old woman was referred with general lethargy and fatigue. Her serum sodium was $122 \mathrm{mmol} / \mathrm{L}$ (normal range 135-145 mmol/L). You suspect that she has the syndrome of inappropriate antidiuresis. Which one of 
the following findings would be most typical for this syndrome?

(a) plasma osmolality of $300 \mathrm{mOsm} / \mathrm{kg}$

(b) serum potassium of $3 \mathrm{mmol} / \mathrm{L}$

(c) urinary sodium excretion of $10 \mathrm{mmol} / \mathrm{L}$

(d) urine osmolality of $320 \mathrm{mOsm} / \mathrm{kg}$

(e) urine output of $2.5 \mathrm{~L} / 24$ hours.

5 Which of the following statements about hyponatraemia is accurate?

(a) Confusion and coma often ensue when serum sodium approaches $125 \mathrm{mmol} / \mathrm{L}$.

(b) In heart failure, it is associated with a poor prognosis.

(c) In liver cirrhosis, it is often due to increased renal loss of sodium.

(d) In the presence of low urea and low serum potassium, it is suggestive of Addison's disease.

(e) When associated with hypo-osmolarity, hyperglycaemia should be considered.

6 A 50-year-old gentleman was brought into the emergency department after he was found unconscious. He had a seizure on arrival. His laboratory results are as follows:

Plasma sodium $101 \mathrm{mmol} / \mathrm{L}$ (normal range 135-145)

Potassium $4.4 \mathrm{mmol} / \mathrm{L}$ (normal range 3.5-5.0)

Urea $3.0 \mathrm{mmol} / \mathrm{L}$ (normal range 2-7)

Creatinine $79 \mu \mathrm{mol} / \mathrm{L}$ (normal range 45-85)

Random blood glucose $8.8 \mathrm{mmol} / \mathrm{L}$.

Chest X-ray showed an apical lung lesion.

Which of the following is the most appropriate next step in his management?
(a) democycline
(b) fluid restriction
(c) frusemide
(d) hypertonic saline
(e) isotonic saline.

7 A 58-year-old woman was admitted to the acute general medical take with nausea, vomiting, confusion and hypotension. She was known to have an estrogen receptor positive invasive ductal carcinoma of the breast and had previously undergone mastectomy with primary reconstruction and was on estrogen deprivation therapy in the form of an aromatase inhibitor. Initial blood biochemistry revealed an adjusted serum calcium level of $3.5 \mathrm{mmol} / \mathrm{L}$ (normal range 2.1-2.6), phosphate $0.6 \mathrm{mmol} / \mathrm{L}$ (normal range $0.8-1.4$ ), alkaline phosphatase of $89 \mathrm{IU} / \mathrm{L}$ (normal range 44-147), parathyroid hormone (PTH) $6.8 \mathrm{pmol} / \mathrm{L}$ (normal range 1.6-6.9) and $25 \mathrm{OH}$ vitamin D $122 \mathrm{nmol} / \mathrm{L}$ (normal range 50-120). The best fit diagnosis for the cause of her hypercalcaemia was:

(a) ectopic PTH production from her known breast carcinoma

(b) humoral (PTHrP-mediated) hypercalcaemia of malignancy (c) primary hyper parathyroidism

(d) vitamin D toxicity

(e) widespread skeletal metastases.

8 A 73-year-old woman with asymptomatic primary hyperparathyroidism was seen in the outpatient clinic and assessed in order to make a recommendation about the best management plan. She had no past medical history of nephrolithiasis. Her estimated glomerular filtration rate was found to be $73 \mathrm{~mL} / \mathrm{min} / 1.73 \mathrm{~m}^{2}$, adjusted serum calcium was $2.75 \mathrm{mmol} / \mathrm{L}$ (normal range 2.1-2.6), lowest T score on a DEXA scan was -2.0 and a renal ultrasound scan showed ultrasonographically normal kidneys. Her $25 \mathrm{OH}$ vitamin D level was $51 \mathrm{nmol} / \mathrm{L}$ (normal range $50-120 \mathrm{nmol} / \mathrm{L}$ ). The best management plan to recommend to her based on these data was:
(a) cinacalcet therapy
(b) conservative management
(c) oral bisphosphonate therapy
(d) parathyroidectomy
(e) vitamin D supplementation.

9 Which of the following statements regarding carbimazole monotherapy is correct?
(a) A treatment course of titration monotherapy is 6 months.
(b) Agranulocytosis occurs more commonly with doses of $>40$ mg per day.
(c) It is more efficacious than a block and replace regimen.
(d) It is the treatment of choice in the first trimester of pregnancy.
(e) White cell counts should be routinely monitored.

10 Which of the following statements regarding radioiodine is correct?
(a) Iodine-123 is used as a first-line therapy for thyrotoxicosis due to Graves' disease.
(b) It is the treatment of choice for toxic nodular disease.
(c) There is an increase in overall cancer risk after radioiodine therapy for thyrotoxicosis.
(d) Thionamides should not be withdrawn prior to radioiodine treatment.
(e) With lower doses, there are no restrictions on close physical contact with others.

\section{CME Cerebrovascular disease SAQ} Answers to the CME SAQ published in Clinical Medicine in April 2017

$\begin{array}{llllllllll}\text { Q1 } & \text { Q2 } & \text { Q3 } & \text { Q4 } & \text { Q5 } & \text { Q6 } & \text { Q7 } & \text { Q8 } & \text { Q9 } & \text { Q10 } \\ \text { (e) } & \text { (e) } & \text { (d) } & \text { (a) } & \text { (e) } & \text { (e) } & \text { (d) } & \text { (d) } & \text { (c) } & \text { (e) }\end{array}$

